\title{
Discovery of Gold Nanoparticles in Marcellus
}

\section{Shale}

Seungyeol Lee ${ }^{1,2,3}$, Huifang $\mathrm{Xu}^{1, *}$, Jenelle Wempner ${ }^{1}$, Hongwu $\mathrm{Xu}^{4}$, and Jianguo Wen

${ }^{1}$ Department of Geoscience, University of Wisconsin-Madison, Madison, WI 53706, USA

${ }^{2}$ USRA Lunar and Planetary Institute, 3600 Bay Area Boulevard, Houston, TX 77058, USA.

${ }^{3}$ ARES, NASA Johnson Space Center, 2101 NASA Parkway, Houston, TX 77058, USA.

${ }^{4}$ Earth and Environmental Sciences Division, Los Alamos National Laboratory, NM 87545, USA

${ }^{5}$ Center for Nanoscale Materials, Argonne National Laboratory, Lemont, IL 60439, USA

*Corresponding author: Prof. Huifang Xu, Email: hfxu@geology.wisc.edu 


\section{Description of materials.}
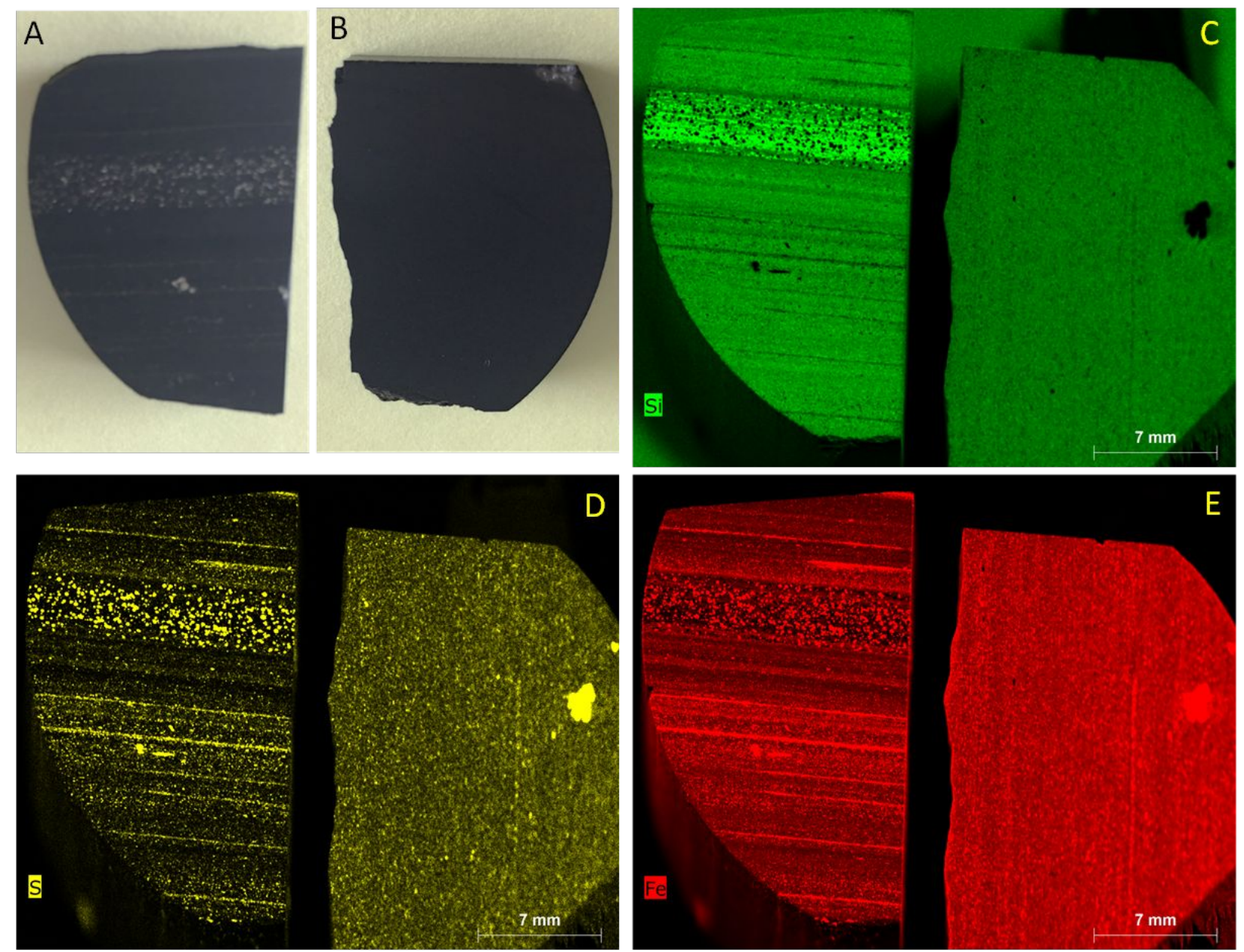

Figure S1. (A) A photograph of organic-poor Marcellus shale, (B) A photograph of organic-rich

Marcellus shale, and (C-E) X-ray elemental mapping ( $\mathrm{Si}, \mathrm{S}$, and $\mathrm{Fe}$ ) of both shale samples.

The samples are Marcellus Shales (often referred as the Marcellus Formation) from a middle Devonian unit at the base of the Hamilton Group. Marcellus shales consisted of 
quartz, illite, chlorite, albite, and pyrite. Total organic contents (TOCs) of the two samples are 3.9 wt. \% (shale in Figure S1A) and 7.5 wt. \% (shale in Figure S1A), respectively. The photograph image of organic-rich Marcellus shale shows the poorly laminated textures, while that of organic-poor Marcellus shale show poorly laminated. The gold nanoparticles and opal-A nanospheres observed in both samples.
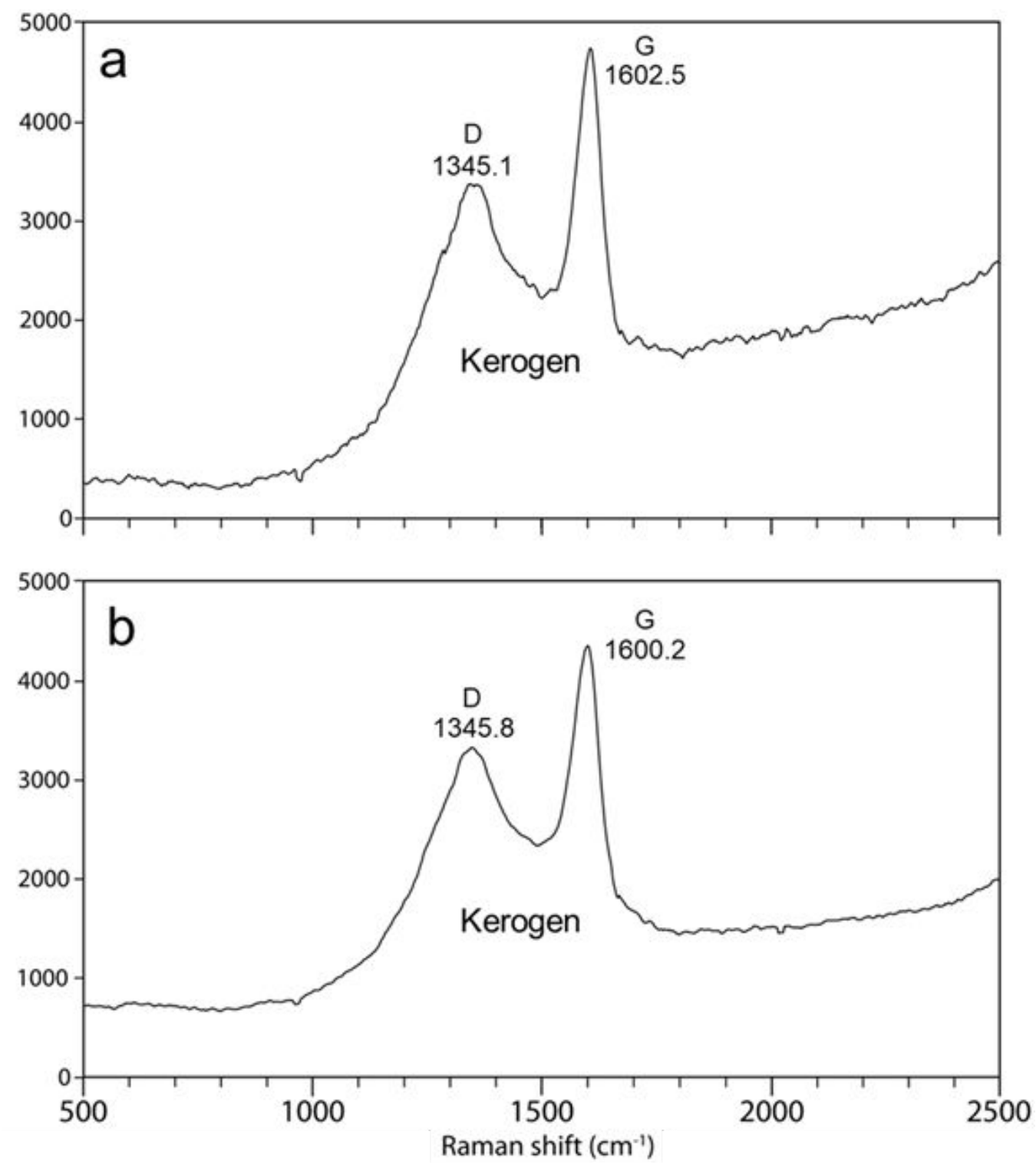
Figure S2. Raman spectra of kerogen in Marcellus shales: (a) High-TOC and (b) Low-TOC. The peak $D$ and peak $G$ in Raman scattering of organic matter reflect the structures and thermal evolution of carboniferous solid organics in geological samples.
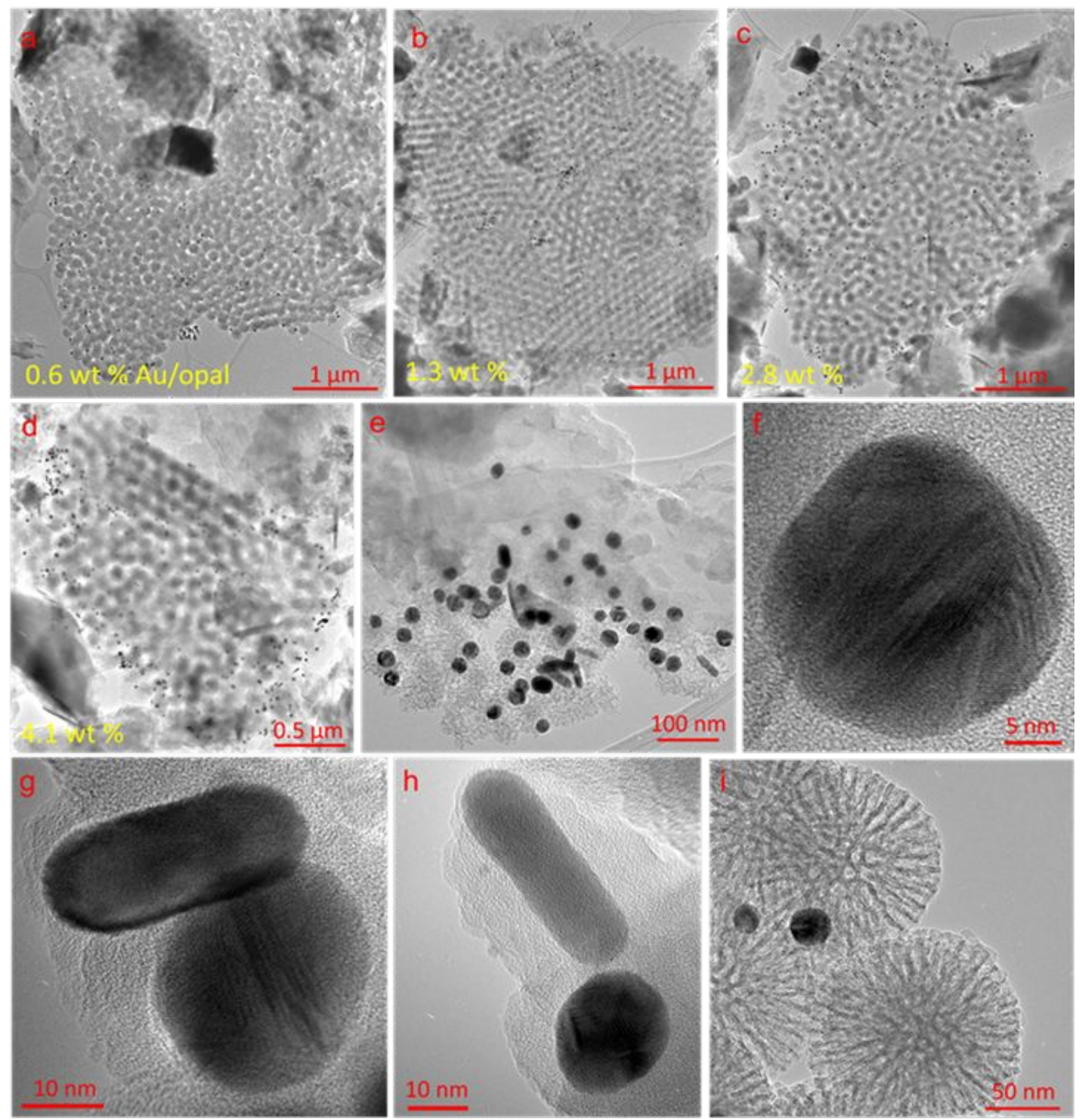

Figure S3. Low magnified bright-field TEM images of gold nanoparticles with the opal nanospheres (a-b) high-TOC and (c-d) low-TOC, showing the gold concentration (weight percent of Au per opal); (e) An area of high density of gold nanoparticles; (f-h) high resolution TEM image 
of gold nanoparticles; (g) high resolution TEM image of mesoporous opal nanospheres.
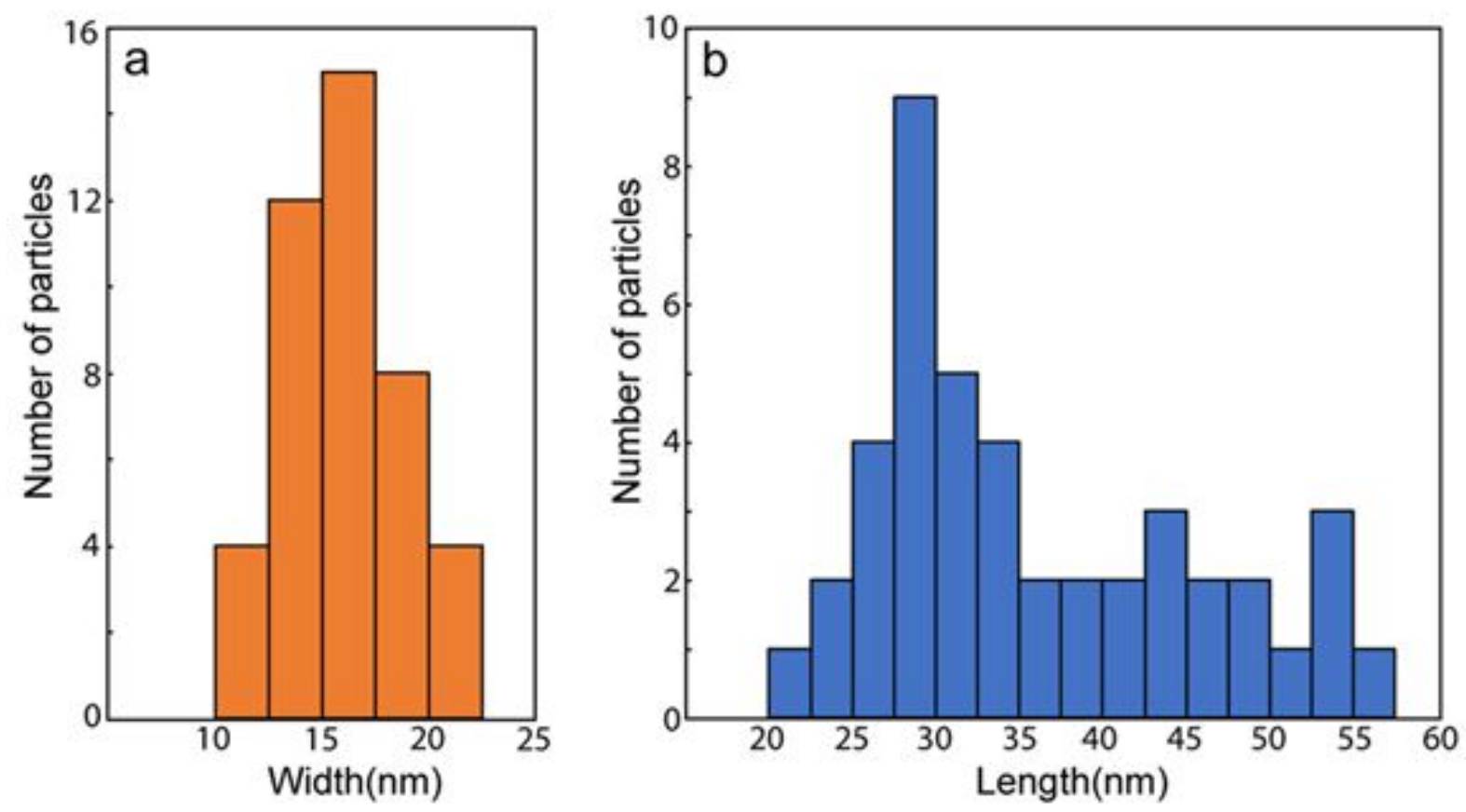

Figure S4. Size distribution histogram related to the width and length of gold nanorods determined from TEM images. 

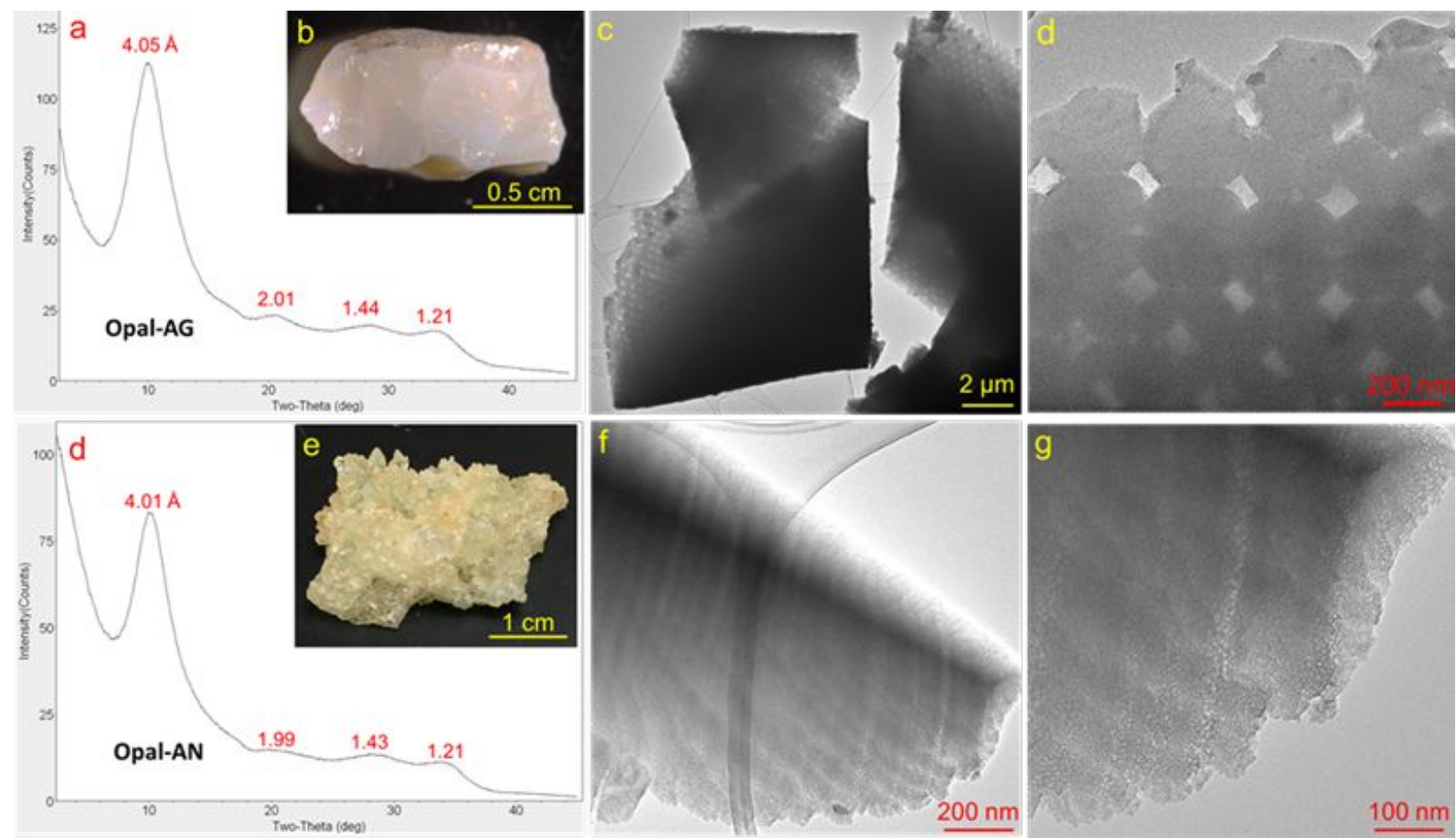

Figure S5. (a-c) Powder X-ray diffraction pattern, optical image and bright-field TEM image of precious opal AG with iridescent colors and (d-f) opal-AN without iridescent colors from Chalic mine, North Carolina. 


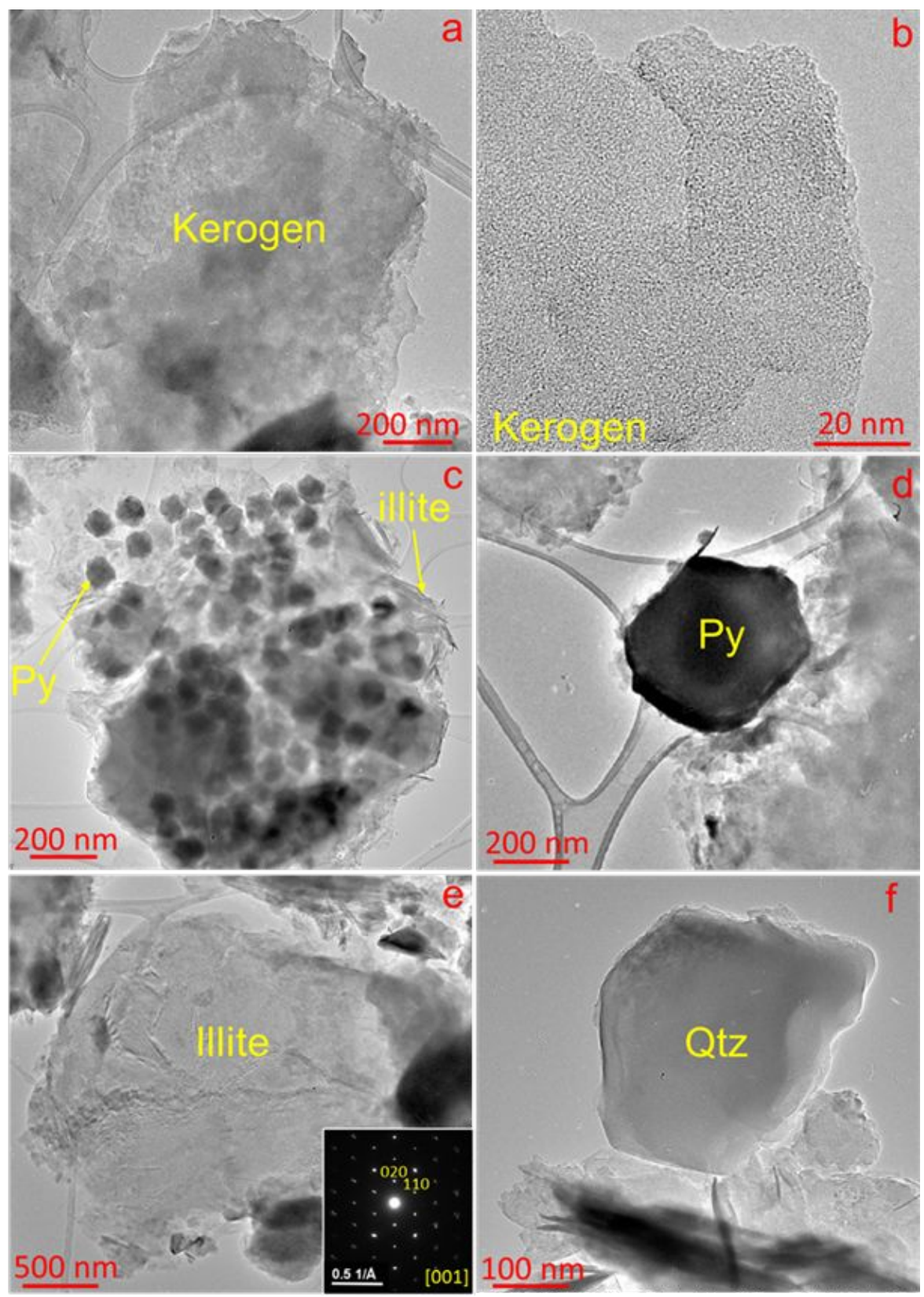

Figure S6. Bright-field TEM images of kerogen, pyrite (Py), illite, and quartz (Qtz) in Marcellus shale. Inserted SAED pattern is from the illite crystal (e). 


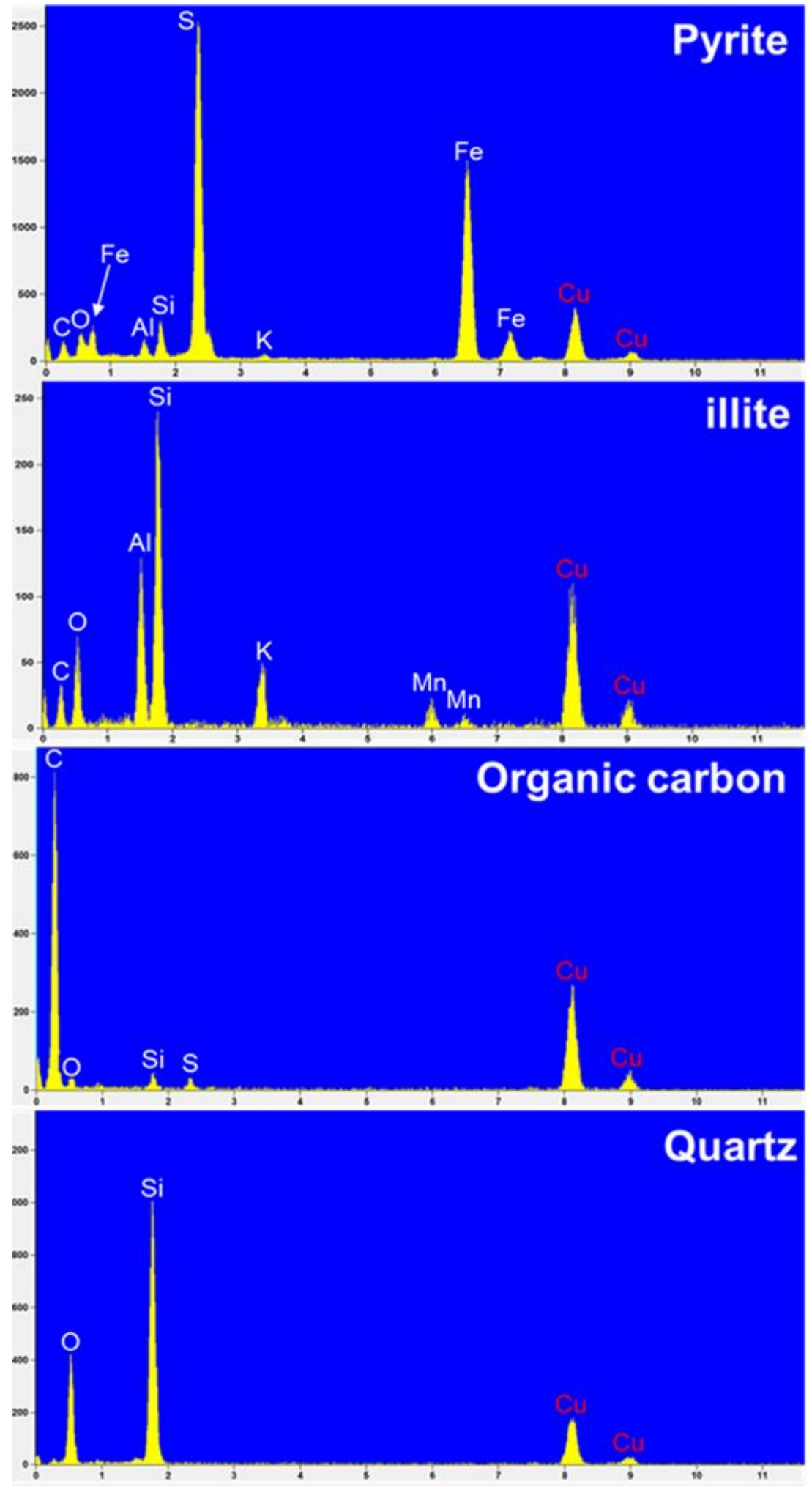

Figure S7. X-ray EDS spectra of pyrite, illite, organic carbon (kerogen), and quartz. 


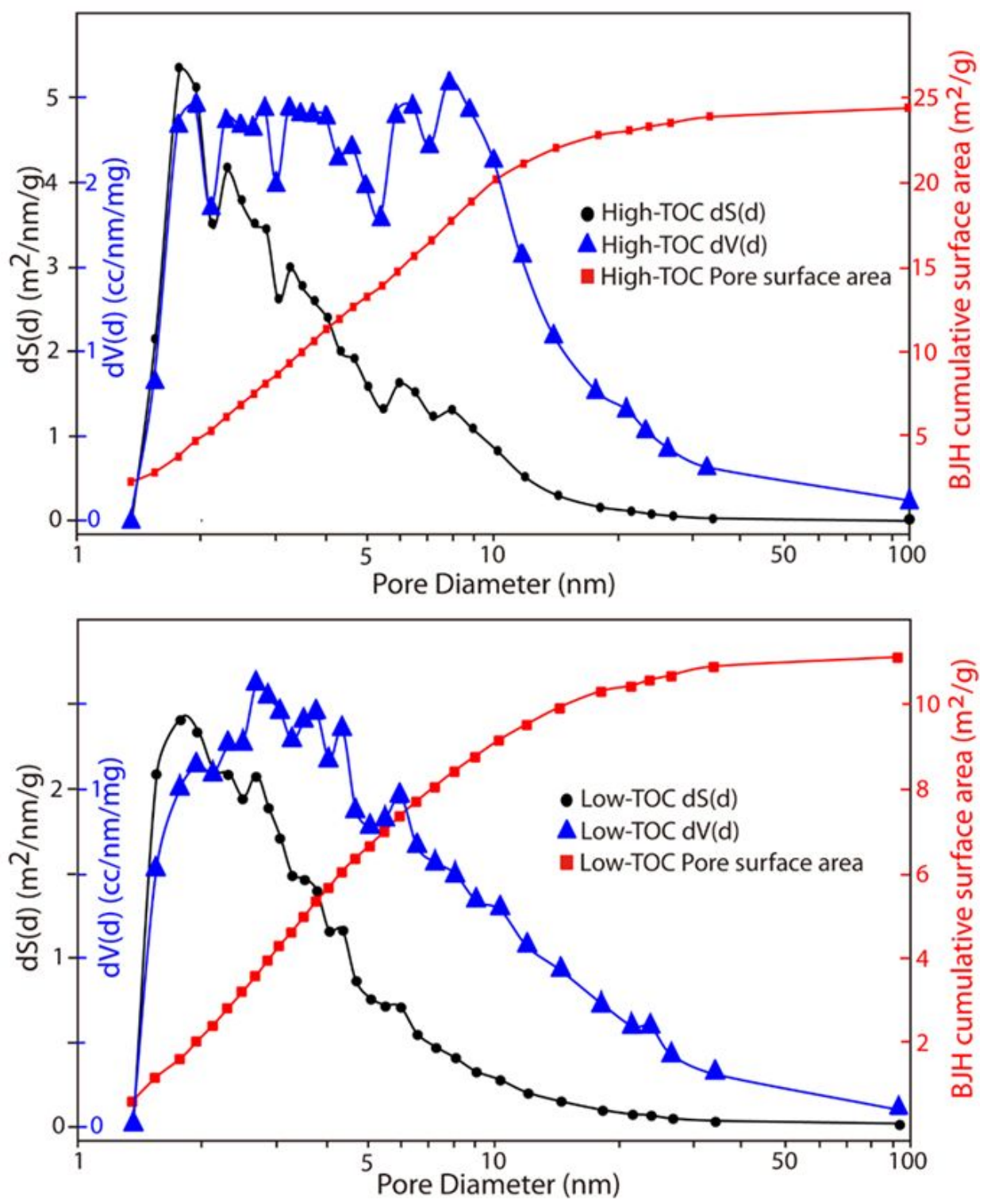

Figure S8. Diagrams illustrating BJH pore size distributions and cumulated surface areas for Marcellus shales: High-TOC and Low-TOC. Pore size distribution $(\mathrm{dS}(\mathrm{d}), \mathrm{m} 2 / \mathrm{nm} / \mathrm{g})$ is the derivative of surface area as a function of pore diameter. 


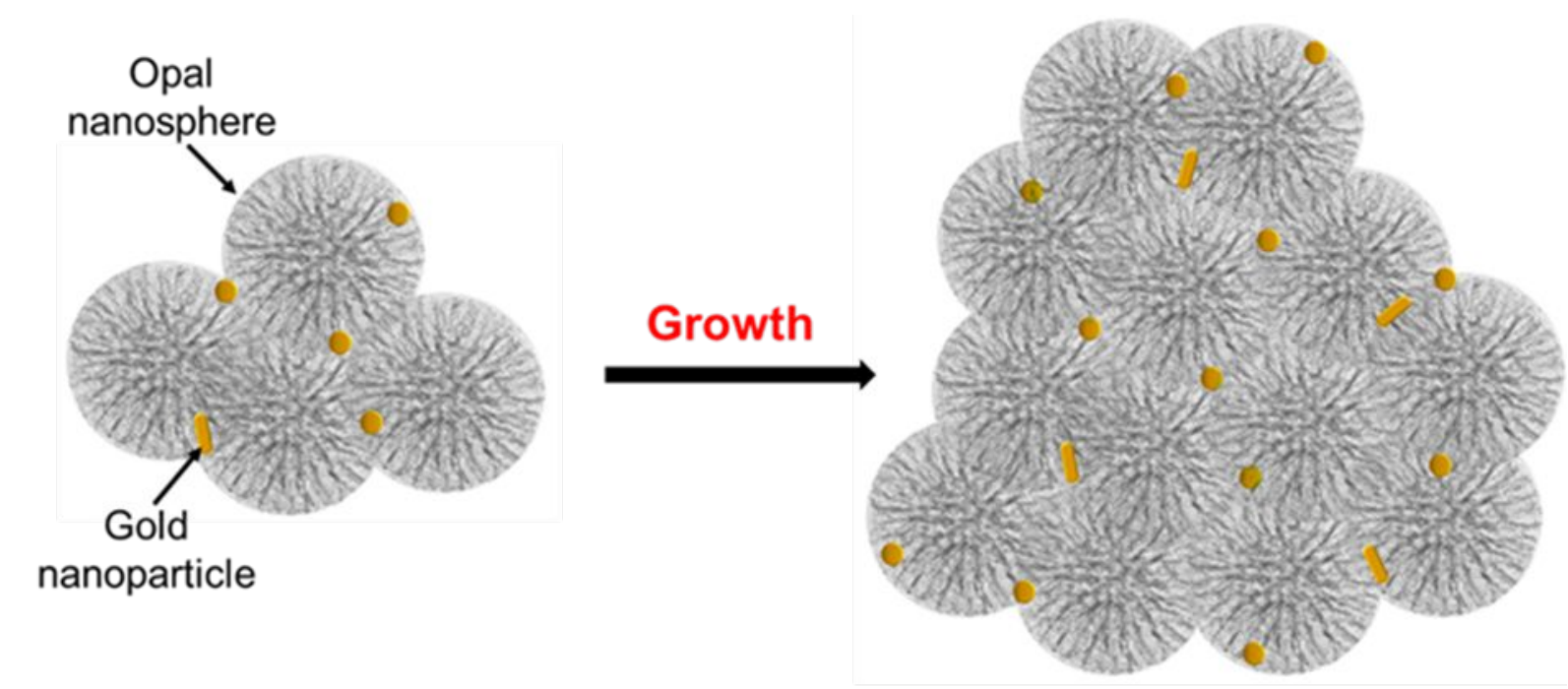

Opal precipitation $\rightarrow$ local $\mathrm{pH}$ increase $\rightarrow$ Gold precipitation

\begin{tabular}{c|c|}
$\mathrm{H}_{3} \mathrm{SiO}_{4}^{-}+\mathrm{H}_{4} \mathrm{SiO}_{4}=$ & $\mathrm{Au}(\mathrm{HS})+\mathrm{Au}(\mathrm{HS})_{2}^{-}+\mathrm{H}_{2} \mathrm{O}=$ \\
$2 \mathrm{SiO}_{2}(\mathrm{~s})+3 \mathrm{H}_{2} \mathrm{O}+\mathrm{OH}^{-}$ & $2 \mathrm{Au}(\mathrm{s})+3 \mathrm{HS}^{-}+2 \mathrm{H}^{+}+1 / 2 \mathrm{O}_{2}$
\end{tabular}

Figure S9. Schematic diagram illustrating the formation of gold nanoparticles on opal nanospheres. 
Table S1 TOC, Raman parameters, surface area measurement (BET and BJH) for Marcellus Shale samples.

\begin{tabular}{ccccc}
\hline Sample & TOC & Raman reflectance* & BET $^{* *}$ & BJH $^{* * *}$ \\
\hline High-TOC & 7.50 wt. $\%$ & 2.61 & $15.55 \mathrm{~m}^{2} / \mathrm{g}$ & $24.38 \mathrm{~m}^{2} / \mathrm{g}$ \\
Low-TOC & 3.90 wt. $\%$ & 2.45 & $6.93 \mathrm{~m}^{2} / \mathrm{g}$ & $11.18 \mathrm{~m}^{2} / \mathrm{g}$ \\
\hline
\end{tabular}

*Raman reflectance $=0.0537 d(\mathrm{G}-\mathrm{D})-11.21$ (Liu et al., 2013).

** Brunauer-Emmett-Teller (BET) surface area method

*** Barrett-Joyner-Halenda (BJH) surface area method 


\section{ADDITIONAL REFERENCES CITED}

(1) Liu, D., Xiao, X., Tian, H., Min, Y., Zhou, Q., Cheng, P., Shen, J. 2013 Sample maturation calculated using Raman spectroscopic parameters for solid organics: Methodology and geological applications. Chinese Sci Bull 58(11), 1285-1298. 